\title{
CHOREOGRAPHIC MORPHOLOGIES: DIGITAL VISUALISATION OF SPATIO-TEMPORAL STRUCTURE IN DANCE AND THE IMPLICATIONS FOR PERFORMANCE AND DOCUMENTATION
}

\author{
Helen Bailey \\ James Hewison \\ Faculty of Creative Arts, \\ Faculty of Creative Arts, \\ Technologies \& Science \\ Technologies \& Science \\ University of Bedfordshire, \\ University of Bedfordshire, \\ UK \\ UK \\ Helen.Bailey@beds.ac.uk James.Hewison@beds.ac.uk
}

Martin Turner

Research Computing

Manchester University,

UK

mt@manchester.ac.uk

\begin{abstract}
This paper discusses the role and function of visualisation within practice-led research in dance. In particular it focuses on the Choreographic Morphologies Project (2007). This practice-led research project explored the use of digital visualisation as an integral component within live performance; as a mode of performance documentation and as a visual score for further re-iterative, creative/research engagement.
\end{abstract}

\section{INTRODUCTION}

This paper considers the role of digital visualisation in choreography, dance performance and documentation. It will focus on presenting research findings from the 2007 practice-led dance/technology project Choreographic Morphologies. The main research aims of the Choreographic Morphologies project were firstly; to utilise a range of digital technologies to capture and visualise choreographic/compositional structure. And secondly, to consider the multiple applications of these visualisations as: an integral component within live performance; as a mode of performance documentation and as a visual score for further iterative, creative/research engagement.

The project resulted in the creation of the dance work - Morphologies, a 20-minute piece for four dancers and a live string quartet interacting in real-time with a virtual 3-D environment. This final practice-led outcome of the project integrated dance, live music and digital technologies in an exploration of the visualisation of spatio-temporal compositional structure and experiential embodied/performative spatialities across the domains of dance and music. This was explored through the integration of motion capture, stereoscopic digital video projection and motion-tracking software in order to create a 3D interactive environment for performance. This paper will discuss the various technologies used in both the creative process and in the performance context as a means of capturing and visualising spatio-temporal compositional structure choreographic morphologies. There are several key implications that arise from this research and that will be explored here. Firstly, what is the relationship of the 'virtual' to the 'ephemeral' in the context of this kind of live, mediatised performance? Secondly what is the status and/or identity of the choreographic object or artefact in this intersecting conceptual and interdisciplinary context? These questions lead into interesting convergences in territories generally associated with disciplines concerned with the materiality of culture and experience: and specifically that of archaeology. 


\section{CONTEXT}

Choreographic Morphologies contributes to the larger e-Dance project [1]. e-Dance is a two-year interdisciplinary practice-led research project, running from September 2007 until September 2009. It brings together practitioners and academics from the fields of Dance and e-Science. The research is funded by three UK Research Councils; AHRC, EPSRC and JISC [2]. This collaborative, interdisciplinary project is led by the University of Bedfordshire and involves researchers from the University of Manchester, University of Leeds and the Open University as well as dance artists from the professional, independent dance sector.

In making use of recent e-Science developments in the visualisation of structure and discourse, the e-Dance project addresses two intersecting questions. Firstly, what unique opportunities does e-Science provide for developing new approaches to choreographic process/composition and for capturing/modelling practice-led research? Secondly, how can choreographic knowledge and sensibility enable e-Science to make its applications more usable within performance/arts practice-led research?
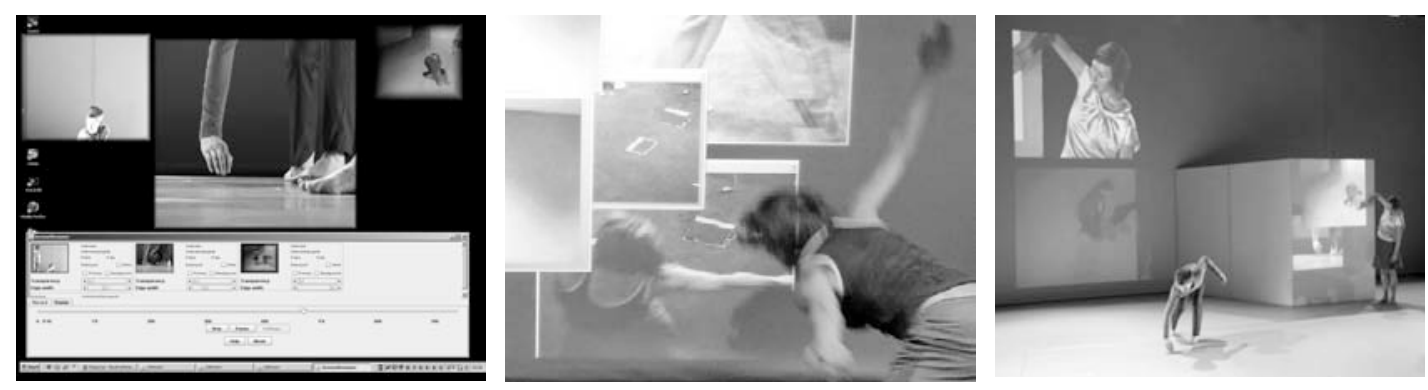

Figure 1. e-Dance Project (2007-09), Access Grid as telematic performance and documentation environment. Dancers: Catherine Bennett and James Hewison performing Space/Placed, University of Bedfordshire UK

Morphologies also builds on research findings from Bailey, Garcia, Hewison and Turner's previous practice-led interdisciplinary research project Stereobodies (2006) [3], which formed part of the JISC funded VRE:1 project CSAGE: Collaborative Stereoscopic Access Grid Environment, led by Manchester University's Visualisation Centre. The Stereobodies project focused on the use of stereoscopic video in both networked and non-networked performance contexts as a means of enhancing performer/spectator perception of the presence of the virtual dancer. The project specifically focussed on exploring the representation of the virtual dancer in a threedimensional configuration that challenged the aesthetic framing more commonly associated with two-dimensional projected video in multi-media performance practices. The Stereobodies project provided the context for a series of practice-led experiments in the use of stereoscopic video technology to explore the notion of touch and physical contact between the live and virtual performer enabled through the construction of this 3-D virtual space [4]. It was during this research that the current team developed an understanding of the impact of stereoscopic video on live performance in terms of creating an immersive environment that heightened the sense of presence of the virtual performer from the spectatorial position. Although this 

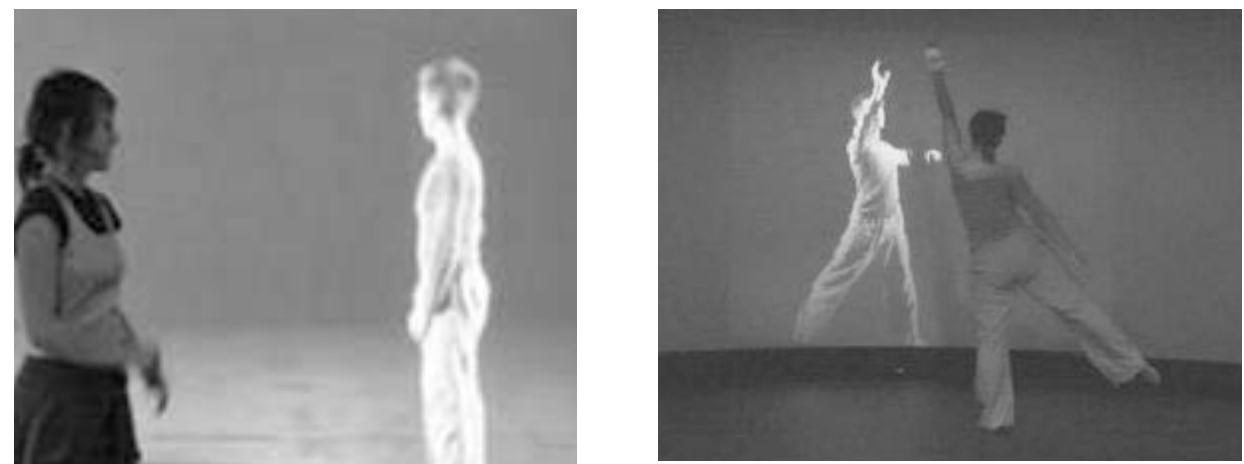

Figure 2. Stereobodies performed by Amalia Garcia and James Hewison, University of Manchester, UK (2006)

research resulted in some compelling work-in-progress performance outcomes it was restricted to the use of video representations of actual performers in either pre-recorded or live telematic modes. The Choreographic Morphologies project sought to develop on this and to use the technology to integrate digitally generated visual objects within the space of live performance.

\section{PROCESS}

The research methodology for the project was collaborative and practice-led. It involved a studio-based creative engagement with the aims of the research and included collaboration with four professional dance artists [5], three of whom are also dance academics. Although the project had some specific research aims, which have already been summarised above, concerning the use and application of various technologies to performance and documentation: the project also necessitated a creative artist-led engagement, which was less explicit. The creative starting point and conceptual framework for the piece was also concerned with the notion of structure, but specifically its relationship to perception. For this the choreographic explorations employed a phenomenological lens, focusing on the first-person experience of the dancers in the generation and performance of structure. This was used as a means for both understanding and framing the performers' creative engagement with spatiotemporal structure of both movement and sound during the creative process. The project worked with live music and had access to the string quartet throughout the creative process.

In discussions with the dance artists we fore-grounded the significance of their shifting experience of space: moving from and between the geometric to the interpersonal; the proximal to the narrative and the relative to the mediated. In particular this conceptual starting point focussed on a practical engagement with Merleau Ponty's later and incomplete work, The Visible and Invisible [6]. In this opaque text MerleauPonty draws out the complexity in his previously articulated concept of reversibility, in which a procedure of ontological reversal takes place in terms of the subject's experiential encounter with, in and through the world. He suggests that the visual is seen as the dominant mode of engagement. However vision and the visible are not viewed by Merleau-Ponty as strictly equating to a subject-object relationship. 


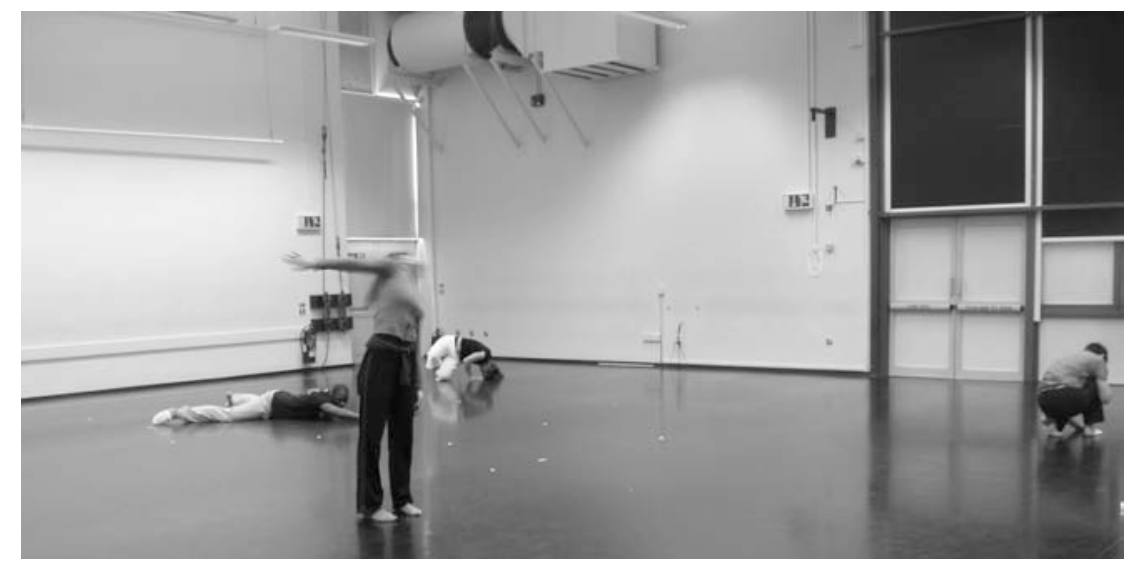

Figure 3. Choreographic Morphologies studio-based research with dance artists: Lee Awanah, Amalia Garcia, James Hewison and Lisa Spackman, University of Bedfordshire, UK

"The visible about us seems to rest in itself. It is as though our vision were formed in the heart of the visible, or as though there were between it and us an intimacy as close as between the sea and the sand." [7] The movement between the seeing and seen is replicated in his discussion of the reversibility of touch. In the context of dance, touch is as significant a sensory mode of navigation and engagement as the visual. "As a communicative act... touch... incorporates the social interface as it dissolves the boundaries between subject and object. Acts of touching, as cultural events, presuppose affective encounters - the relation between "being touched" and "being moved"[8]. The Choreographic Morphologies project is predicated on this notion of reversibility across a range of dichotomies at stake within the context of inter-medial practices. We explored the notion of the synaesthetic body of the dancer vis-à-vis visual/aural/motile/tactile spatialities of composition in the digital mediated environment. This gave us a way in to the concept of reversibility in creative, embodied, performative terms "...the synaesthetic system (is an) extension of the nervous system beyond the body... such a synaesthetic system is perceived by the tactile modality of proprioception in discerning the performative context as a volumetric or "charged space." [9]

The dancer's relationship to music could be generally understood as essentially synaesthetic. There is a choreographic method known as 'music visualisation' that was developed during early twentieth century Dance Modernism in Europe and Northern America [10]. This requires a direct equivalence between musical and choreographic concepts: for instance; pitch becomes level, volume becomes size, tempo equates to movement speed and musical phrasing, accents and so on are exactly replicated within the movement structure. As a key proponent of this method, Modernist Choreographer Ruth St Denis suggested this was best achieved without recourse to the dancer's subjective experience. It is in this sense that the methodology used in this process is divergent from this Modernist configuration. In this process the experiential knowledge of the performer is of central significance, a tactile rather than visual synaesthetic relationship with the music was explored. For the project we worked with the Aria and a selection of seven of the Variations from J.S. Bach's Goldberg Variations. The felt experience of the music, articulated through movement, was a central generative, improvisatory task in the construction of the Aria Response Solo from which the digital visualisation was produced and subsequently reciprocally connected. Pre-reflective 
improvisatory responses to the sound-score of the Aria from Bach's Goldberg Variations were established as a generative movement task, the dancers were asked to work with closed eyes and to respond, in the moment, to the tactility of the music, perceived as an immersive auditory environment. This hyper-reflective looping [11] improvisation formed the basis for the Aria Response Solo and is a phenomenological account or response to the Bach Aria. The digital visualisation is a further iteration of this process.

Once the Aria Response Solo was complete and fixed, the material was then converted into data using a video motion-capture system, in which visual sensors were attached to the dancer's body. We specifically selected positions on the body

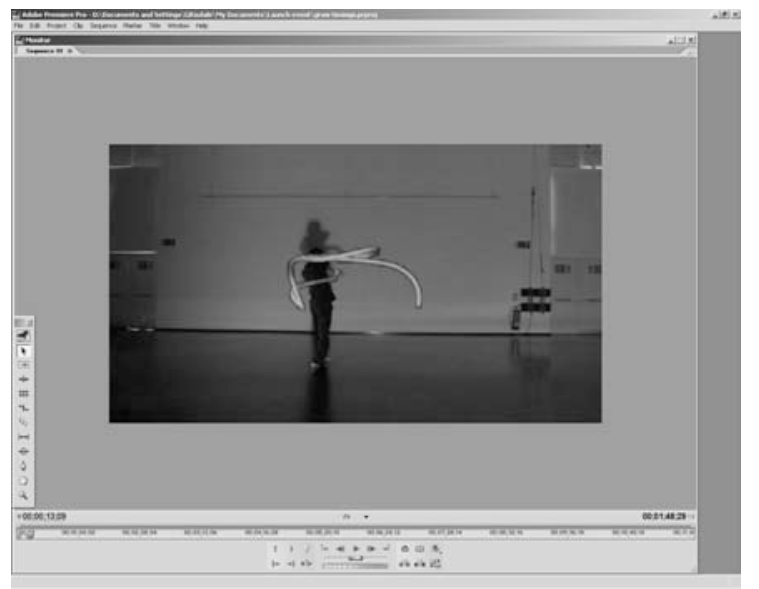

Figure 4. Composite image of motion capture data, digital animation and rehearsal video of the Aria Response Solo. Dancer: James Hewison (2007)

that articulated the dominant spatial trajectory at any given moment within the multidirectional movement material. We were aiming to produce, once animated, a continuous intertwining strip that mapped the solo in four dimensions. This data would then be controlled using the propriety software Isadora developed by Mark Coniglio, Co-Director of US-based dance technology company Troika Ranch. "Isadora is a graphic programming environment that provides interactive control over digital media, with special emphasis on real-time manipulation of digital video" [12].
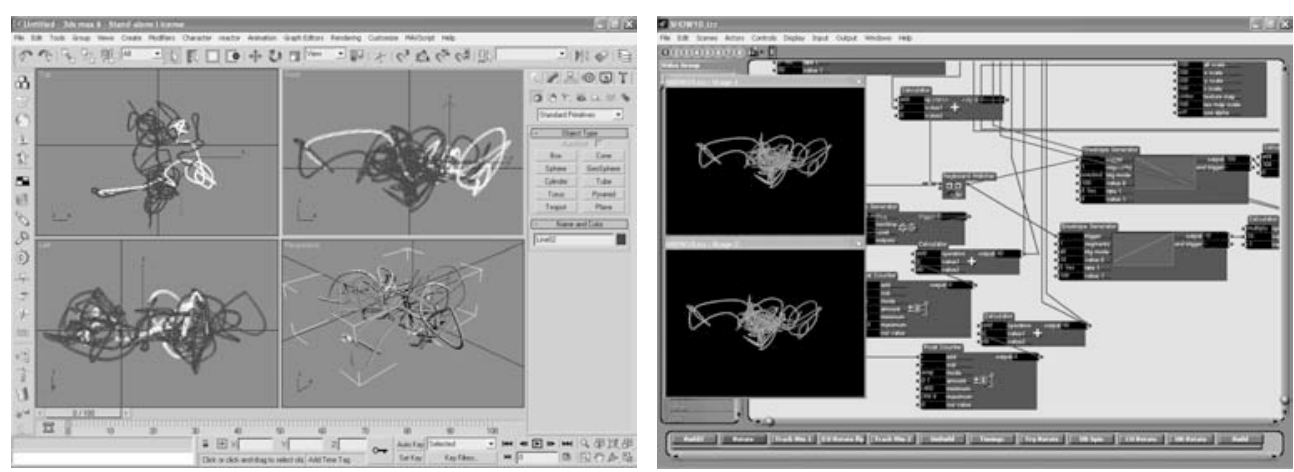

Figure 5: Screen shots of the construction of the 3-D digital visualisation using 3dsmax and Isadora

Figures 6 and 7 provide images of the digital object that was generated as a result of the motion capture data being graphically animated using 3 dsmax software. 


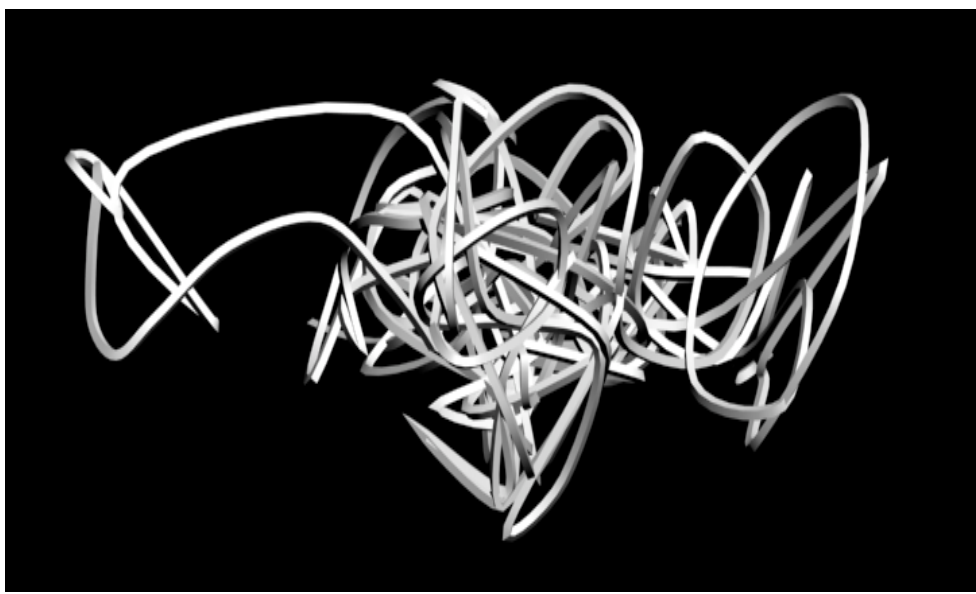

Figure 6. Choreographic Morphology (front perspective)

The aim was to then project this data using two parallel data projectors onto a polarised screen to create a stereoscopic image of this 3-D visualisation. Once the animation was complete, it was possible to work directly with the digital object in the rehearsal studio. Although it was not stereoscopic at this stage, the three

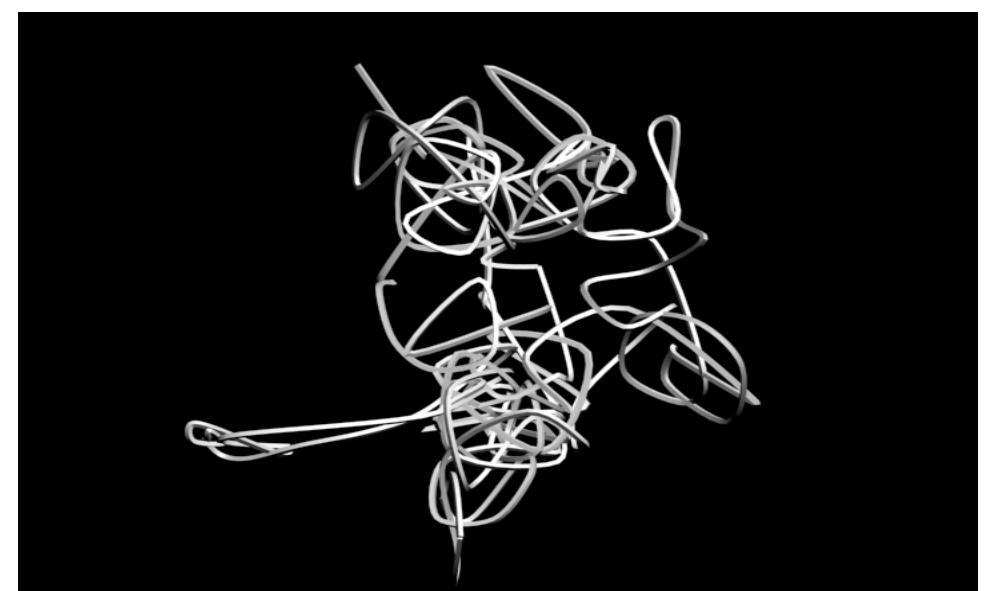

Figure 7. Choreographic Morphology (overhead perspective)

dimensionality of the visualisation provided directional clarity for us in terms of being able to engage with it within the creative process and have the opportunity to reflect on its properties from a research perspective.

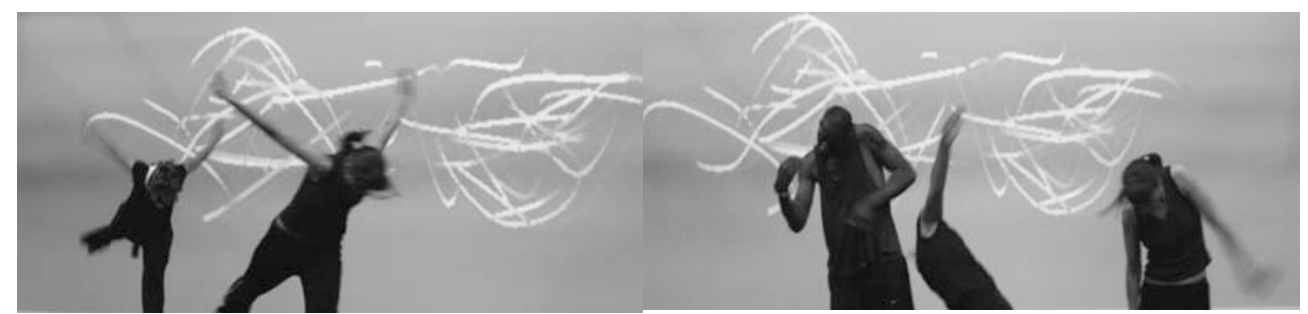

Figure 8. Rehearsal process with the digital object. Dancers: Lee Awanah, Amalia Garcia and Lisa Spackman, University of Bedfordshire, UK (2007) 
It was apparent that when the virtual object was static, not animated and in its 'end' state ( see figures $6 \& 7$ ), in other words, when the movement was complete, we had produced an a-temporal visualisation of the solo. Once the visualisation was fully integrated into the live performance context, the object's temporal unfolding was controlled interactively by the motion of the performer in real-time. In this context the object was both spatially and temporally connected to the live performer. And through the use of stereoscopic projection, the performers appeared to directly inhabit the virtual terrain, mapped out by the digital object.

During the studio-based research phase of the project, which took place during August-September 2007, we visited the Anthony Gormley's Blind Light exhibition at the Hayward Gallery, London. It was as a result of seeing Gormley's sculpture Feeling Material XXIX, (2007) that we realised that what we were creating, through this mediatisation of the compositional structure, was in one sense a piece of sculpture, albeit virtual. We had unconsciously enacted a further disciplinary migration.

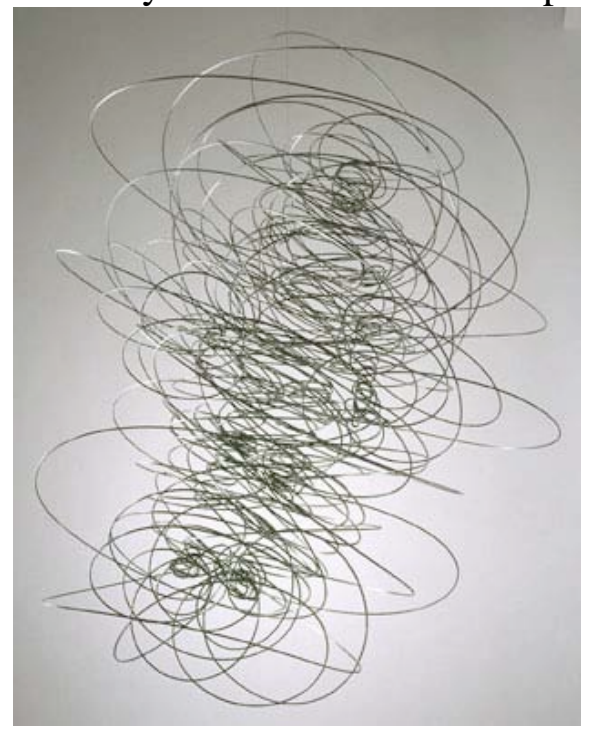

Figure 9. Feeling Material XXIX, (2007) by Anthony Gormley

It was the absent presence of the body, the arrested motion and the sense of corporeality embodied both in the work and in our engagement with it that clarified this. In the interview with Gormley included in the Exhibition Catalogue, it is clear to see the impact (conscious or otherwise) of phenomenological frameworks on his practice. His choice of language to describe the process of creating the work is enthused with the terminology and sentiments of Phenomenology. When discussing the use of his own body within his art practice he suggests "...this allows me to make work from inside my material, as it were. The activity of moulding is the capturing of an event, an embodied moment of human time captured in matter." [13]

From a compositional perspective Morphologies focuses on the generative capacity of the performer to produce proximal, inter-subjective spatialities and the tracing of this process via the technologies integrated into the work. The visual technologies function as an amplifier of this process, in their capacity to visualise motional traces and to problematise the dimensional, spatial separation of the projected, digital image from the live dancing embodied subject. 


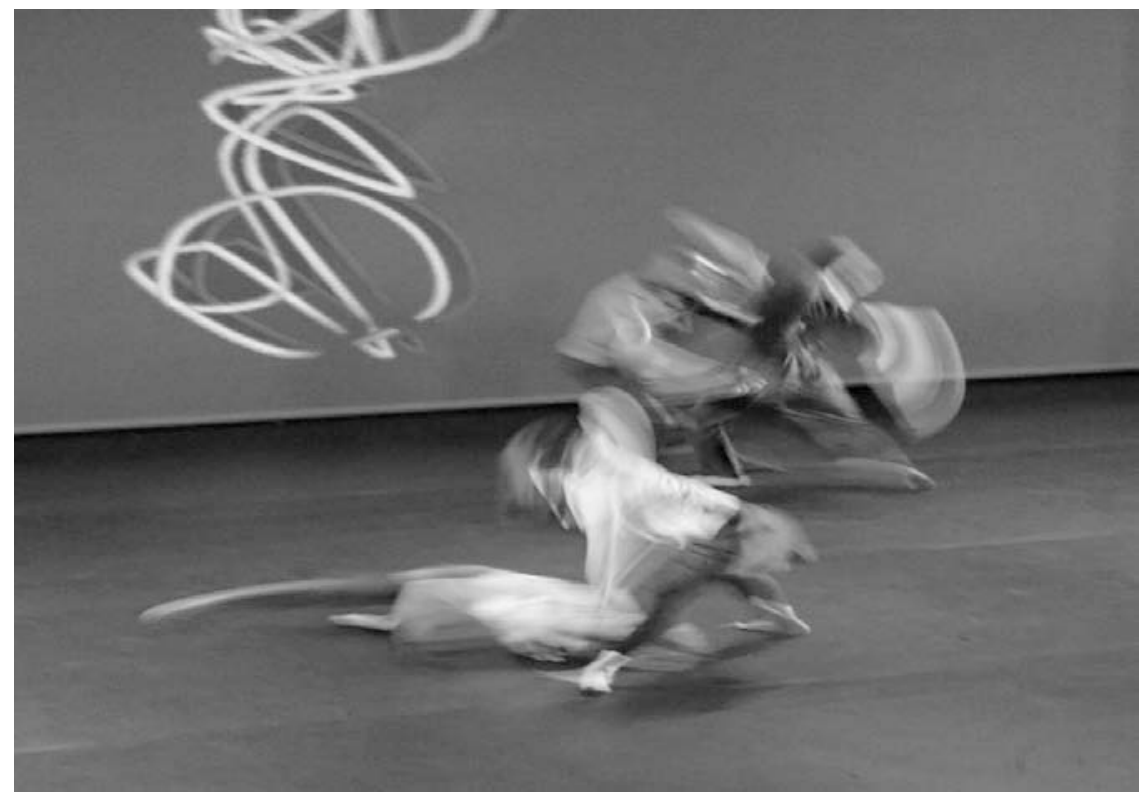

Figure 10. First public performance of Morphologies, October 2007.

Dancers: Lee Awanah, Amalia Garcia, James Hewison and Lisa Spackman

\section{IMPLICATIONS}

The process of visualisation set out in Choreographic Morphologies produces a permanent trace of ephemeral or virtual movement pathways - providing a visual score of the spatio-temporal design of the composition. The techniques employed allowed the generation of a digital object that visualised the choreographic morphology of the dance work as a virtual sculpture. This then became a score to be mined almost archaeologically as a means of generating further compositional methodology and choreographic material. Therefore subsequent compositional approaches emerged from this initial aim.

Choreographic Morphologies provides an essential role for the dancer as the locus or site of the performative embodiment of the choreography. This is an example of performative documentation based on the spatio-temporal specificity of event [14] rather than the platonic, disembodied a-temporal documentation provided by notation systems such as Labanotation. In this sense it is more akin to the topology of archaeological methodology, the partial recovery of momentary, transient dwellings, behaviours and the recuperation of the corporeal memory of this experience, as opposed to the notation systems that are predicated on the contingency of the performer in fixing both the identity and status of the choreographic object. In the case of Choreographic Morphologies the 'score' or documentation becomes physical, albeit virtual and particular as opposed to abstracted, conceptual and therefore generalised. The choreography itself can be seen as a form of spatial notation, an ephemeral but no less material rendering of socio-cultural formulations of space. Shanks and Pearson state in Theatre/Archaeology - "Archaeology is to regard itself as a practice of cultural production, a contemporary material practice which works on and with traces of the past and within which the archaeologist is implicated as an active agent of interpretation... Rather than being a reconstruction of the past from surviving remains, this is a recontextualisation." [15] 

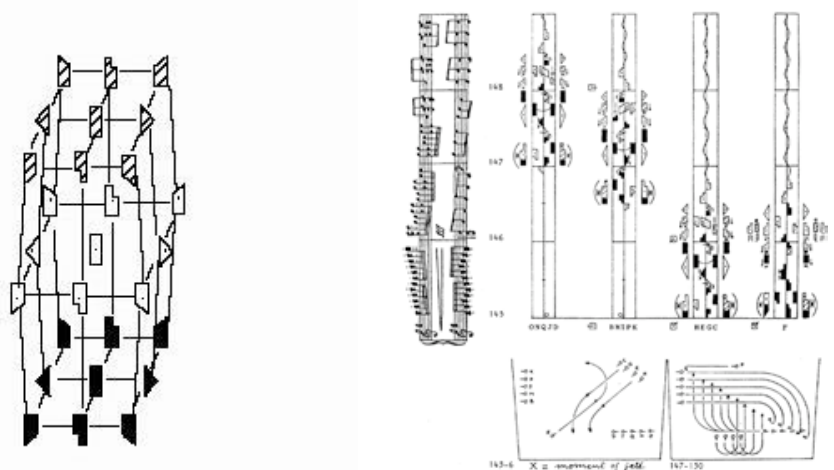

Figure 11. Spatial directions codified through Labanotation, and a Labanotation score including music notation and floor patterns

Gormley talks about his sense of connection to archaeology - "my concerns are existential and anthropological... I look as much to anthropology and archaeology as to art: they open up possibilities. Who art can be for, why it's there at all, who can feel connected to it, how it works - these are more important questions than the evolution of sculpture for its own sake." [16]

The traditional dichotomy of the virtual and the real is not useful or perhaps appropriate in this context. The digital object or virtual sculpture that was generated as a result of Choreographic Morphologies is no less real because of its virtual status. It performs the space; it articulates and marks a set of positions. It demonstrates its presence alongside that of the performers, in one sense it is an extension of the performers body, in another it demonstrates its agentic presence as distinct from, yet intimately implicated in its relationship to them. Dance Artist, James Hewison who performed the Aria Response Solo in the final work Morphologies, states of his relationship to the virtual sculpture - "...viewing the shape outside of performance, standing back and looking at it as an object in its own right, I think it is a magnificent thing. In fact I don't perceive it as something created in response to something I have done. It is too complex and whole, and has too much of an identity for that. It is easier to imagine me travelling along its various paths (like a luge run) than to imagine it unravelling after me. I would very much like to hold it - have it generated as a physical, three-diemsional object" [17].

Peggy Phelan provided a clear definitional parameter for the ontology performance concerning the foundational relationship of disappearance to the act of performance [18]; this is a particularly compelling argument in the context of a performance discipline that draws attention to the performer's bodily inscription of space and time through motion. However by the very nature of this focus on motility, it undermines the argument, not in the sense provided by Auslander [19] concerning the role of mediatisation, but through the very concept of the virtual. But in this sense an understanding of the virtual that is not synonymous with the digital. Dancers enact a virtual trace in time and space irrespective of digital mediation. It is this virtual spatiotemporal trace that as with the Derridean footprint is paradoxically both present and absent. It is also the invisible extension into space and time that can only be witnessed through the cognitive/kinaesthetic leap made by the spectator. It is this that Choreographic Morphologies attempts to capture, render visible and knowable. 


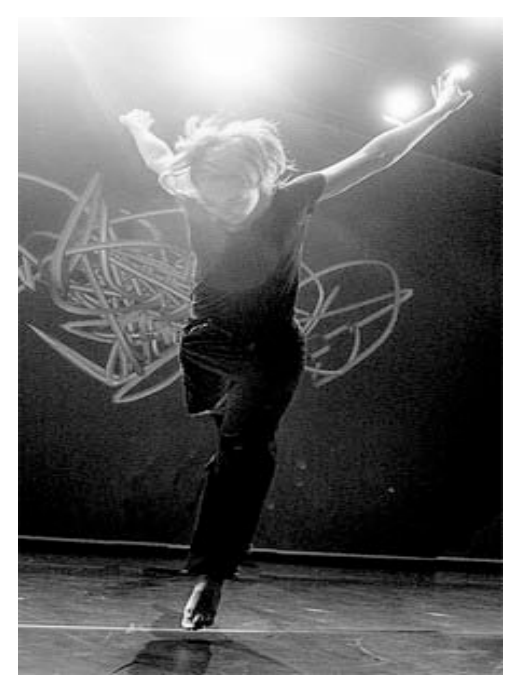

Figure 12. Dancer; Amalia Garcia performing Morphologies (2007)

\section{ACKNOWLEDGMENTS}

We would like to thank Gareth Risdale, Head of Technical Production in the Department of Performing Arts \& English at the University of Bedfordshire for his technical skill and support in the realisation of Morphologies.

\section{References}

[1] e-Dance Project website: www.ahessc.ac.uk/e-dance

[2] http://www.ahrcict.rdg.ac.uk/activities/e-science/awards_2007.htm

[3] Stereobodies website: http://kato.mvc.mcc.ac.uk/rss-wiki/SAGE/StereoBodies

[4] BAILEY, H. (2007) "ersatz dancing: Negotiating the live and mediated in digital performance practice" in the International Journal of Performing Arts and Digital Media, Vol.3 No.2-3 Pgs 151-165, Intellect

[5] Collaborative dance artists: Lee Awanah, Amalia Garcia, James Hewison, Lisa Spackman

[6] MERLEAU-PONTY, M. (1968 trans.) "The Visible and the Invisible”, published in Baldwin, T (ed.) (2004) Maurice Merleau-Ponty: Basic Writings, Routledge

[7] ibid. Pg. 249

[8] Pg.167, Fisher, J "Tangible Acts" in BANES, S. and LEPECKI, A. (eds) (2006) The Senses in Performance, Routledge

[9] ibid. Pg.176

[10] "Music visualisation in its purest form is the scientific translation of bodily action of the rhythmic, melodic and harmonic structure of the musical composition, without intention to 'interpret' or reveal any hidden meaning apprehended by the dancer." Ruth St Denis, circa 1915, cited in PRESTON-DUNLOP, V. (1995) Dance Words, Routledge

[11] Pg.22 KOZEL, S. (2007) Closer: Performance, Technologies, Phenomenology, MA: MIT Press

[12] Troika Ranch website: http://www.troikaranch.org/technology.html

[13] Pg. 40, Gormley, A., cited in VIDLER, A., STEWART, S., MITCHELL, W.J.T (2007) Anthony Gormley: Blind Light, South Bank Centre, Hayward Publishing

[14] BADIOU, A., (2007) Being and Event, Coninuum

[15] Pg.11 PEARSON, M., Shanks, M. (2001) Theatre/Archaeology, Routledge

[16] opcit Pg.42 Gormley, A.

[17] HEWISON, J. (2007) Interview, unpublished.

[18] Pg.146 Phelan, P. (1993) Unmarked: The Politics of Performance, Routledge

[19] AUSLANDER, P., (1999) Liveness: Performance in a Mediatized Culture, Routledge 